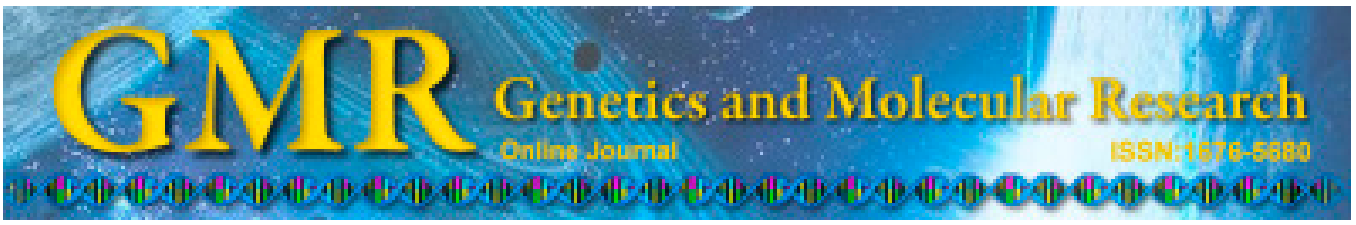

\title{
Effects of intravenous analgesia with combined dezocine and butorphanol on postoperative cognitive function in elderly patients
}

\author{
B.X. Ren, J. Zong, J.C. Tang, D.P. Sun, X. Hui, R.Q. Li, J.L. Zhang and Y. Ji \\ Department of Anesthesiology, Affiliated Hospital of Jiangnan University, \\ Wuxi, Jiangsu Province, China \\ Corresponding author: B.X. Ren \\ E-mail: renbingxu_rbx@163.com
}

Genet. Mol. Res. 14 (2): 5571-5576 (2015)

Received July 22, 2014

Accepted October 21, 2014

Published May 25, 2015

DOI http://dx.doi.org/10.4238/2015.May.25.8

\begin{abstract}
The aim of this study was to observe the analgesic effects of the combination of dezocine and butorphanol on postoperative cognitive function in elderly patients. Forty elderly patients undergoing upper abdominal surgeries or thoracotomies with general anesthesia were randomly divided into the dezocine and butorphanol group or the butorphanol group (20 patients per group). A visual analog scale was used to evaluate analgesia and the degree of malignant vomiting. The Ramsay scoring method was used to evaluate sedation. The Mini-Mental State Examination (MMSE) was used to evaluate cognitive function. Forty-eight hours after the operation, the pain score of the dezocine and butorphanol group (means $\pm \mathrm{SD}, 1.75 \pm 0.44$ ) was lower than that of the butorphanol group $(2.25 \pm 0.79 ; \mathrm{P}<0.05)$, and the nausea and vomiting score of the dezocine and butorphanol group (0) was lower than that of the butorphanol group $(0.70 \pm 1.30 ; \mathrm{P}<0.05)$. Six hours after the operation, the sedative score of the butorphanol group (3.75 \pm $0.79)$ was higher than that of the dezocine and butorphanol group (2.15 $\pm 0.75 ; \mathrm{P}<0.05)$. Compared to 1 day before the operation, the MMSE
\end{abstract}


scores of both groups decreased $6 \mathrm{~h}$ after the operation, and the MMSE score of the butorphanol group $(15.00 \pm 2.00)$ was lower than that of the dezocine and butorphanol group $(20.95 \pm 1.54 ; \mathrm{P}<0.05)$. Dezocine and butorphanol analgesia had transient effects on postoperative cognitive function in elderly patients, and the effect of the combination was superior than butorphanol only.

Key words: Dezocine; Butorphanol; Postoperative analgesia; Elderly; Postoperative cognitive dysfunction

\section{INTRODUCTION}

Postoperative cognitive dysfunction is a severe postoperative complication that occurs in elderly patients and heavily influences the postoperative recovery and quality of life of the patients (Hartholt et al., 2012; Rundshagen, 2014). Postoperative pain is the most common acute pain, and it is often a clinical emergency. Opioids are the main drugs used for postoperative analgesia. Studies have reported that postoperative cognitive dysfunction is related to the use of opioids (Gagliese et al., 2005; Hartholt et al., 2012). Dezocine and butorphanol, which belong to the opioid receptor agonist-antagonist family, have been increasingly used for postoperative analgesia in recent years. It is unknown whether the combination of dezocine and butorphanol intravenous analgesia has effects on postoperative cognitive function in elderly patients. This study examined the effects of intravenous analgesia with dezocine and butorphanol on the postoperative cognitive function of elderly patients undergoing upper abdominal surgeries or thoracotomies.

\section{MATERIAL AND METHODS}

\section{Materials}

Forty elderly patients undergoing upper abdominal surgeries or thoracotomies with ages from 65-80 years old, with American Society of Anesthesiologists levels of I-II, and with body mass indexes of $18.5-23.9 \mathrm{~kg} / \mathrm{m}^{2}$, were enrolled in the study. The cases did not have serious preoperative cardiopulmonary kidney diseases, nervous system diseases, hearing obstacles, histories of psychiatric drugs and sedative drug abuse, and/or histories of alcoholism. The study protocol was approved by the ethics committee of Jiangnan University, and the patients signed informed consent forms. The patients were randomly divided into Group I (combined dezocine and butorphanol group) and Group II (butorphanol group), with 20 cases in each group.

\section{Methods}

\section{Anesthesia method}

Before the operation, all the patients fasted for $8-12 \mathrm{~h}$. Thirty minutes before the operation, intramuscular injections of $0.1 \mathrm{~g}$ of phenobarbital sodium and $0.5 \mathrm{mg}$ of atropine were administered. An intravenous injection of propofol ( $2 \mathrm{mg} / \mathrm{kg})$, fentanyl $(5 \mu \mathrm{g} / \mathrm{kg})$, and cisatracurium besylate $(0.2 \mathrm{mg} / \mathrm{kg})$ was performed after breath tube intubation, and intermittent positive 
pressure ventilation was then conducted. The end tidal $\mathrm{CO}_{2}$ was maintained at $35-45 \mathrm{mmHg}$. Propofol (100-200 $\mu \mathrm{g} / \mathrm{kg} / \mathrm{min})$, remifentanil $(0.1-0.2 \mu \mathrm{g} / \mathrm{kg} / \mathrm{min})$, and cisatracurium besylate (1-3 $\mu \mathrm{g} / \mathrm{kg} / \mathrm{min}$ ) were administered through a continuous intravenous pump. Thirty minutes before the end of surgery, remifentanil was stopped, and then fentanyl $(0.1 \mathrm{mg})$ was given. The loading doses of the analgesic pump were $2 \mathrm{mg}$ of dezocine and $0.5 \mathrm{mg}$ butorphanol for Group I and $1 \mathrm{mg}$ butorphanol for Group II. The analgesic pumps were turned on at the same time. The formula for Group I was $25 \mathrm{mg}$ of dezocine, $8 \mathrm{mg}$ of butorphanol, and $3 \mathrm{mg}$ of granisetron, while that for Group II was $13 \mathrm{mg}$ of butorphanol and $3 \mathrm{mg}$ of granisetron, both of which were diluted with normal saline to $150 \mathrm{~mL}$. The continuous intravenous pump speed was $3 \mathrm{~mL} / \mathrm{h}$, and the two groups received 3-mL bolus doses each time, with time locked at $15 \mathrm{~min}$ and a maximum dose of $9 \mathrm{~mL} / \mathrm{h}$. After spontaneous breathing was fully recovered, the endotracheal tube was removed. Vital signs and various evaluation indicators were observed after the operation.

\section{Observation indicators}

1) Pain: A visual analog scale (VAS) was used to evaluate pain (Wu et al., 2012). A score of 0 was considered painless, and a score of 10 was considered as intense pain. Scores of 4 and below were considered mild pain (pain does not affect sleep), and scores of 5 to 6 were considered moderate pain (pain influences sleep, but the patients can still fall asleep). Scores of 7 and above were considered severe pain (Due to the pain the patient is unable to sleep or wakes up). 2) Sedative level: The Ramsay method was used to evaluate the sedative level (Rosenstock et al., 2012) with the following scores: Score of 1: awake, and the patient is anxious, upset, or restless; Score of 2: awake, patient is cooperative, with good orientation or quiet; Score of 3: awake and only responds to a command; Score of 4: asleep, and the patient is responsive to a tap on the eyebrow or a strong acoustic stimulus; Score of 5: asleep, and the patient responds slowly to a tap on the eyebrow or a strong acoustic stimulation; and Score of 6: asleep, and there is no response to a tap on the eyebrow or a strong acoustic stimulation. Scores of 2-4 were considered appropriate sedation, while scores of more than 5 were considered excessive sedation. 3) Nausea and vomiting: The VAS method was used to score this from 0 to 10 (Tao et al., 2013). Scores of 1-4 were mild, 5-6 were medium, and 7-10 were severe. 4) Cognitive function: The Mini-Mental State Examination (MMSE) was used to evaluate mental state (Huang et al., 2011). The assessment content included orientation (full score: 10 ), memory (full score: 3 ), attention and computing power (full score: 5 points), ability to recall (full score: 3 ), and language skills (full score: 9). Scores of 27 to 30 were considered to be normal, and scores below 27 were considered to reflect cognitive dysfunction. The severity classification method for the MMSE was the following: mild, $\geq 21$; moderate, 10-20; and severe, $\leq 9$. The baseline value (T0) was measured 1 day before surgery, and postoperative function was evaluated $6 \mathrm{~h}$ (T1), $24 \mathrm{~h}$ (T2), $48 \mathrm{~h} \mathrm{(T3),} \mathrm{and} 72 \mathrm{~h}$ after surgery (T4). All of the tests were conducted in a blind fashion by the same researchers.

\section{Statistical processing}

The SPSS 16.0 software (IBM Corporation, Armonk, NY, USA) was used for the statistical analysis. The measurement data are reported as means $\pm \mathrm{SD}$. A single-factor analysis of variance was adopted between internal comparisons in the group. P values less than 0.05 were considered to be statistically significant. 


\section{RESULTS}

\section{Comparison of the general conditions of the two groups}

There were no statistically significant differences $(\mathrm{P}>0.05)$ for age, Body Mass Index, surgery time, blood loss quantity, awakening time, or extubation time between the two groups. (Table 1)

Table 1. Comparison of the general conditions of the two groups.
\begin{tabular}{lccccccc}
\hline Group & Case & Age (years) & $\begin{array}{c}\text { Weight index } \\
\left(\mathrm{kg} / \mathrm{m}^{2}\right)\end{array}$ & $\begin{array}{c}\text { Operation } \\
\text { time }(\mathrm{min})\end{array}$ & $\begin{array}{c}\text { Hemorrhage } \\
\text { quantity }(\mathrm{mL})\end{array}$ & $\begin{array}{c}\text { Sober } \\
\text { time }(\mathrm{min})\end{array}$ & $\begin{array}{c}\text { Tube drawing } \\
\text { time }(\mathrm{min})\end{array}$ \\
\hline $\begin{array}{l}\text { Dezocine } \\
\begin{array}{l}\text { Compound } \\
\text { Butorphanol } \\
\text { (Group I) }\end{array}\end{array}$ & 20 & $70.35 \pm 4.02$ & $21.55 \pm 1.71$ & $178.25 \pm 34.38$ & $291.50 \pm 107.96$ & $15.15 \pm 3.81$ & $26.80 \pm 5.36$ \\
$\begin{array}{l}\text { Butorphanol } \\
\text { (Group II) }\end{array}$ & 20 & $72.85 \pm 3.91$ & $20.90 \pm 1.51$ & $151.75 \pm 33.61$ & $260.50 \pm 77.63$ & $13.95 \pm 3.47$ & $23.90 \pm 6.32$ \\
\hline
\end{tabular}

Sober time refers to the period between cessation of the anesthetic infusion and the patient's consciousness recovery; Tube drawing time refers to the period between cessation of the anesthetic infusion and removing the trachea catheter. Compare the above indicators of two groups, $\mathrm{P}>0.05$.

\section{Comparison of analgesics, sedation, and severe vomiting scores of the two groups}

There were no statistically significant differences $(P>0.05)$ in the pain scores $6 \mathrm{~h}$ and $24 \mathrm{~h}$ after the operation between the two groups. However, $48 \mathrm{~h}$ after the operation, the pain score of the combined dezocine and butorphanol group was lower than that of the butorphanol group $(\mathrm{P}<0.05)$. Six $\mathrm{h}$ after the operation, the sedation score of the butorphanol group was higher than that of the combined dezocine and butorphanol group $(\mathrm{P}<0.05)$, but there was no statistically significant difference $(\mathrm{P}>0.05)$ for sedation scores $24 \mathrm{~h}$ and $48 \mathrm{~h}$ after the operation between the two groups. There was no statistically significant difference $(\mathrm{P}>0.05)$ for nausea and vomiting scores $6 \mathrm{~h}$ and $24 \mathrm{~h}$ after the operation between the two groups. However, $48 \mathrm{~h}$ after the operation, the nausea and vomiting score of the combined dezocine and butorphanol group was lower than that for the butorphanol group $(\mathrm{P}<0.05)$ (Table 2).

Table 2. Comparison of analgesia, sedation, and severe vomiting scores of the two groups.

\begin{tabular}{|c|c|c|c|c|c|c|c|c|c|c|}
\hline \multirow[t]{2}{*}{ Group } & \multirow[t]{2}{*}{ Cases } & \multicolumn{3}{|c|}{ Analgesia (Min.) } & \multicolumn{3}{|c|}{ Calm (Min.) } & \multicolumn{3}{|c|}{ Pernicious vomiting (min.) } \\
\hline & & $6 \mathrm{~h}$ & $24 \mathrm{~h}$ & $48 \mathrm{~h}$ & $6 \mathrm{~h}$ & $24 \mathrm{~h}$ & $48 \mathrm{~h}$ & $6 \mathrm{~h}$ & $24 \mathrm{~h}$ & $48 \mathrm{~h}$ \\
\hline $\begin{array}{l}\text { Dezocine } \\
\text { compound } \\
\text { butorphanol } \\
\text { (Group I) }\end{array}$ & 20 & $2.45 \pm 1.05$ & $2.15 \pm 0.98$ & $1.75 \pm 0.44^{b}$ & $2.15 \pm 0.75^{\mathrm{a}}$ & $2.95 \pm 0.83$ & $2.35 \pm 0.49$ & $1.15 \pm 1.46$ & $1.15 \pm 1.42$ & $0.00 \pm 0.00^{b}$ \\
\hline $\begin{array}{l}\text { Butorphanol } \\
\text { (Group II) }\end{array}$ & 20 & $2.65 \pm 1.18$ & $2.10 \pm 0.91$ & $2.25 \pm 0.79$ & $3.75 \pm 0.79$ & $3.0 \pm 0.86$ & $2.65 \pm 0.75$ & $1.05 \pm 1.39$ & $1.00 \pm 1.34$ & $0.70 \pm 1.30$ \\
\hline
\end{tabular}

Compared to Group II, $6 \mathrm{~h}$ after the operation, ${ }^{\mathrm{a}} \mathrm{P}<0.05 ; 48 \mathrm{~h}$ after the operation, ${ }^{\mathrm{b}} \mathrm{P}<0.05$.

\section{Comparison of the cognitive functions of the two groups}

Compared to the results obtained $1 \mathrm{~d}$ before the operation, both of the MMSE scores 
of the two groups decreased $6 \mathrm{~h}$ after the operation, and the MMSE score of the butorphanol group was lower than that of the dezocine and butorphanol group $(\mathrm{P}<0.05)$. Compared to the results obtained $1 \mathrm{~d}$ before the operation, there were no statistically significant differences $(\mathrm{P}>$ 0.05 ) in the MMSE scores between the two groups 24,48 , and $72 \mathrm{~h}$ after the operation (Table 3 ).

Table 3. Comparison of the cognitive functions of the two groups (MMSE Scoring).

\begin{tabular}{lcccccc}
\hline Group & Cases & $\begin{array}{c}\text { One day before } \\
\text { the operation (T0) }\end{array}$ & $\begin{array}{c}\text { Six h after the } \\
\text { operation (T1) }\end{array}$ & $\begin{array}{c}\text { Twenty-four h after } \\
\text { the operation (T2) }\end{array}$ & $\begin{array}{c}\text { Forty-eight h after } \\
\text { the operation (T3) }\end{array}$ & $\begin{array}{c}\text { Seventy-two h after } \\
\text { the operation (T4) }\end{array}$ \\
\hline $\begin{array}{l}\text { Dezocine compound } \\
\text { butorphanol (Group I) }\end{array}$ & 20 & $28.30 \pm 1.08$ & $20.9 \pm 1.54^{\text {ab }}$ & $26.80 \pm 1.88$ & $27.50 \pm 1.39$ & $28.3 \pm 1.13$ \\
$\begin{array}{l}\text { Butorphanol (Group II) } \\
20\end{array}$ & $28.25 \pm 1.25$ & $15.00 \pm 2.00^{\mathrm{b}}$ & $26.85 \pm 1.98$ & $27.65 \pm 1.18$ & $28.15 \pm 1.21$ \\
\hline
\end{tabular}

Compared to Group II, $6 \mathrm{~h}$ after the operation, ${ }^{a} \mathrm{P}<0.05$; compared to before the operation, ${ }^{\mathrm{b}} \mathrm{P}<0.05$; MMSE, Mini-Mental State Examination

\section{DISCUSSION}

For the patients undergoing upper abdominal surgeries or thoracotomies, higher doses of opioids are often used for postoperative analgesia. Therefore, we chose patients undergoing this kind of surgery as subjects. In recent years, dezocine and butorphanol have been the most commonly used opioid receptor agonist-antagonist in clinical settings, but it is not known whether the use of postoperative high doses will affect the cognitive function of elderly patients. Butorphanol causes sedation and analgesia. In addition, it has a long half-life and strong analgesic action (about 5 times that of morphine). The analgesic intensity and duration of dezocine is equal to those of morphine. The specificity of the receptor for dezocine and butorphanol determines the incidence of respiratory depression. Dezocine and butorphanol cause lesser gastrointestinal side effects with no significant dependence. Their appropriate combination may enhance analgesic actions and reduce side effects. Experts on postoperative analgesia with butorphanol have suggested that the starting dose of butorphanol should be reduced to half for elderly patients and intermittence should be extended to more than twice the normal, or multimodal analgesia should be used. Because the combined use of sedatives and anesthetics may cause or aggravate lethargy, delirium, or cognitive dysfunction (Huang et al., 2011), this study used a control group with patients administered butorphanol-only as postoperative analgesia. There was no statistically significant difference in the pain scores 6 and $24 \mathrm{~h}$ after the operation between the two groups of patients, thus showing that the analgesic effects of the drugs that were used for the two groups were equal at an early stage after the operation. However, $48 \mathrm{~h}$ after the operation, the pain score of the butorphanol group was higher than that of the combined dezocine and butorphanol group, and the follow-up studies showed that this may be related to the fact that the patients stopped using the analgesia pump to avoid excessive sedation with butorphanol. Six hours after the operation, the sedation score in the butorphanol group was higher than that of the combined dezocine and butorphanol group, indicating that butorphanol had stronger sedation, which was similar to the findings of a previous study (Sinha et al., 2012). However, after 24 h, there was no statistically significant difference in the two groups. There were no significant differences in the nausea and vomiting scores 6 and $24 \mathrm{~h}$ after the operation between the two groups of patients. However, $48 \mathrm{~h}$ after the operation, the nausea and vomiting score in the butorphanol group was higher than that in the combined dezocine and butorphanol group, and this might correspond to the long-acting 
time of butorphanol. MMSE scores in the two groups decreased $6 \mathrm{~h}$ after the operation, and the MMSE score of the butorphanol group was lower than that of the dezocine and butorphanol Group. Twenty-four hours, 48, and $72 \mathrm{~h}$ after the operation, the patients in both groups recovered normally. These findings showed that the two groups of drugs transiently influenced cognitive function and that the combination had lesser influence on cognitive function in elderly patients. Studies have shown that dependence occurred when the cerebral ventricle of rats was bathed with butorphanol; the mRNA levels of the NR1 subunit decreased significantly in the cerebral cortex, pituitary, and hippocampal CA1 zone; the mRNA levels of the NR2A subunit increased significantly in the cerebral cortex and the hippocampal dentate gyrus zone; and the mRNA contents of the NR2B subunit decreased in the cerebral cortex, caudoputamen, pituitary, and the hippocampal CA3 zone (Zhu et al., 1999; Oh et al., 2000). The N-methylD-aspartate (NMDA) receptor is closely associated with cognitive function (Rammes et al., 2009; Mawhinney et al., 2012). Future studies should be conducted to determine whether the effects of dezocine and butorphanol on cognitive function are related to the NMDA receptor.

\section{ACKNOWLEDGMENTS}

$$
\text { (\#BK2012102) }
$$

Young National Natural Science Fund (\#81300949), Jiangsu Youth Science Funds

\section{REFERENCES}

Gagliese L, Weizblit N, Ellis W and Chan VW (2005). The measurement of postoperative pain: a comparison of intensity scales in younger and older surgical patients. Pain 117: 412-420.

Hartholt KA, van der Cammen TJ and Klimek M (2012). Postoperative cognitive dysfunction in geriatric patients. $Z$. Gerontol. Geriatr. 45: 411-416.

Huang YG, Huang WQ, Li G, et al. (2011). Tartaric acid bhutto brown analgesia expert consensus. J. Clin. Anesthesiology 27: 1028-1029.

Mawhinney LJ, de Rivero Vaccari JP, Alonso OF, Jimenez CA, et al. (2012). Isoflurane/nitrous oxide anesthesia induces increases in NMDA receptor subunit NR2B protein expression in the aged rat brain. Brain Res. 1431: 23-34.

Oh S, Kim JI, Chung MW and Ho IK (2000). Modulation of NMDA receptor subunit mRNA in butorphanol-tolerant and -withdrawing rats. Neurochem. Res. 25: 1603-1611.

Rammes G, Starker LK, Haseneder R, Berkmann J, et al. (2009). Isoflurane anaesthesia reversibly improves cognitive function and long-term potentiation (LTP) via an up-regulation in NMDA receptor 2B subunit expression. Neuropharmacology 56: 626-636.

Rosenstock CV, Thøgersen B, Afshari A, Christensen AL, et al. (2012). Awake fiberoptic or awake video laryngoscopic tracheal intubation in patients with anticipated difficult airway management: a randomized clinical trial. Anesthesiology 116: 1210-1216.

Rundshagen I. (2014). Postoperative cognitive dysfunction. Dtsch Arztebl Int. 111: 119-125.

Sinha C, Kaur M, Kumar A, Kulkarni A, et al. (2012). Comparative evaluation of midazolam and butorphanol as oral premedication in pediatric patients. J. Anaesthesiol. Clin. Pharmacol. 28: 32-35.

Tao WP, Mao QY and Yang JP (2013). Spinal surgery of family care and postoperative cognitive dysfunction in patients with correlation analysis. Zhonghuaxingweiyixueyunaokexuezazhi 22: 908-910.

Wu XM, Luo AL, Tian YK, et al. (2012). Postoperative nausea and vomiting prevention expert advice. J. Clin. Anesthesiology 28: 413-416.

Zhu H, Jang CG, Ma T, Oh S, et al. (1999). Region specific expression of NMDA receptor NR1 subunit mRNA in hypothalamus and pons following chronic morphine treatment. Eur. J. Pharmacol. 365: 47-54. 